\title{
IMPACTO ECONÓMICO Y SOCIAL DEL FERROCARRIL PANAMERICANO EN LA REGIÓN DE TONALÁ EN EL SIGLO XX
}

\author{
THE PANAMERICAN RAILWAY IN THE TONALÁ REGION, CHIAPAS \\ IN THE TWENTIETH CENTURY: ITS ECONOMIC AND SOCIAL IMPACT
}

Valente Molina Pérez

Candidato a doctor en Estudios Regionales, Universidad Autónoma de Chiapas

narrativadelsur@hotmail.com

\section{RESUMEN}

Este artículo analiza las transformaciones ocurridas en la región de Tonalá, Chiapas, durante el siglo XX, asociadas con la presencia del ferrocarril, fundamentalmente en las dimensiones social y económica. Se revisa la significación de este medio de comunicación terrestre cuyo impacto en esa localidad fue disminuyendo durante el siglo pasado, por cambios en varios órdenes de la vida social, política y económica del estado.

PALABRAS CLAVE: ferrocarril, Tonalá, región, corredor costero, Chiapas.

\section{ABSTRACT}

This article analyzes the social and economic transformations that took place in the region of Tonalá, Chiapas during the twentieth century associated with the presence of the railway. It reviews the significance of this means of land transportation, the impact of which on the Tonala region kept decreasing throughout the twentieth century due to changes in various aspects of social, political and economic life in Chiapas State.

KEY WORDS: railway, Tonalá, region, coastal corridor, Chiapas. 


\section{INTRODUCCIÓN}

E ste trabajo explora los cambios sociales y económicos ocurridos a raíz de la presencia del ferrocarril en la actual región administrativa Istmo-Costa de Chiapas, cuyas demarcaciones estuvieron identificadas por muchos siglos en los dominios del pueblo de Tonalá. Aportaré elementos para revisar cómo ese medio de transporte desde su aparición en los albores del siglo XX se ancló como eje de movimiento para los sectores social y económico, convirtiéndose en elemento identitario de desarrollo local y detonador del crecimiento en muchos sentidos, pero generó quizá otros esquemas no positivos, como un desordenado reordenamiento poblacional y un desequilibrio económico que, aunados a los altibajos en la administración de la compañía ferroviaria, generaron crisis, mal servicio y un final predecible: su privatización, en el ocaso de ese mismo siglo.

Este tema permite entonces revisar cómo se asimiló y amalgamó un medio de transporte con la sociedad, y sus repercusiones económicas a partir de 1900. Me he planteado, pues, las siguientes preguntas: ¿Por qué fue determinante la presencia del ferrocarril? ¿cómo influyó este medio de transporte en la transformación de la región?, ¿qué aportación puede atribuirse al tren respecto de la capacidad productiva local? ¿qué tendencia de reconfiguración social se experimentó en esos cien años?, ¿por qué después de la primera mitad del siglo hubo decaimiento en el sistema de vías?, ¿qué significó localmente la privatización?

Las respuestas de estos y otros cuestionamientos las encontramos en hechos suscitados en varios momentos del «espacio y tiempo en el que todo está ligado a todo y merece redescubrirse y replantearse con nuevos enfoques» (Holscher 1997). En este sentido, es posible analizar el fenómeno generado por la presencia del Ferrocarril Panamericano en la región de Tonalá en tres periodos. El primero abarcaría los años de 1900 a 1920, correspondientes a la introducción del tren; posteriormente, el posrevolucionario, de 1920 a 1960, en que se registra una recuperación estatal en los órdenes social y económico. Finalmente, el último cuarto del siglo marca un descenso notorio en el aporte del tren a la localidad, de 1960 a 2000. 


\section{LA REGIÓN. DEL PUERTO AL TREN}

Al referirnos a Tonalá hablamos de la actual región económica IX Istmo-Costa. ${ }^{1}$ Un territorio que socialmente es identificado como «zona costera», «costanera» «costa chica» o simplemente «La Costa», nombres que aluden a la extensión territorial contigua al istmo de Tehuantepec y al Océano Pacífico, que desde tiempos prehispánicos tuvo como eje social, político y económico al pueblo de Tonalá, cuyo nombre deriva de la palabra Tonatlán (en náhuatl clásico) 'lugar de sol' o 'casa del sol'. 2

En la carta geográfica de 1856, ordenada por el gobernador Ángel Albino Corzo (figura 1), en la distribución de regiones, el pueblo de Tonalá aparece adscrito al departamento de Tuxtla; de ese modo, su cabecera se hallaba muy alejada como para abordar cualquier asunto de carácter administrativo.

Figura 1. Adscripción departamental de Tonalá en 1856.

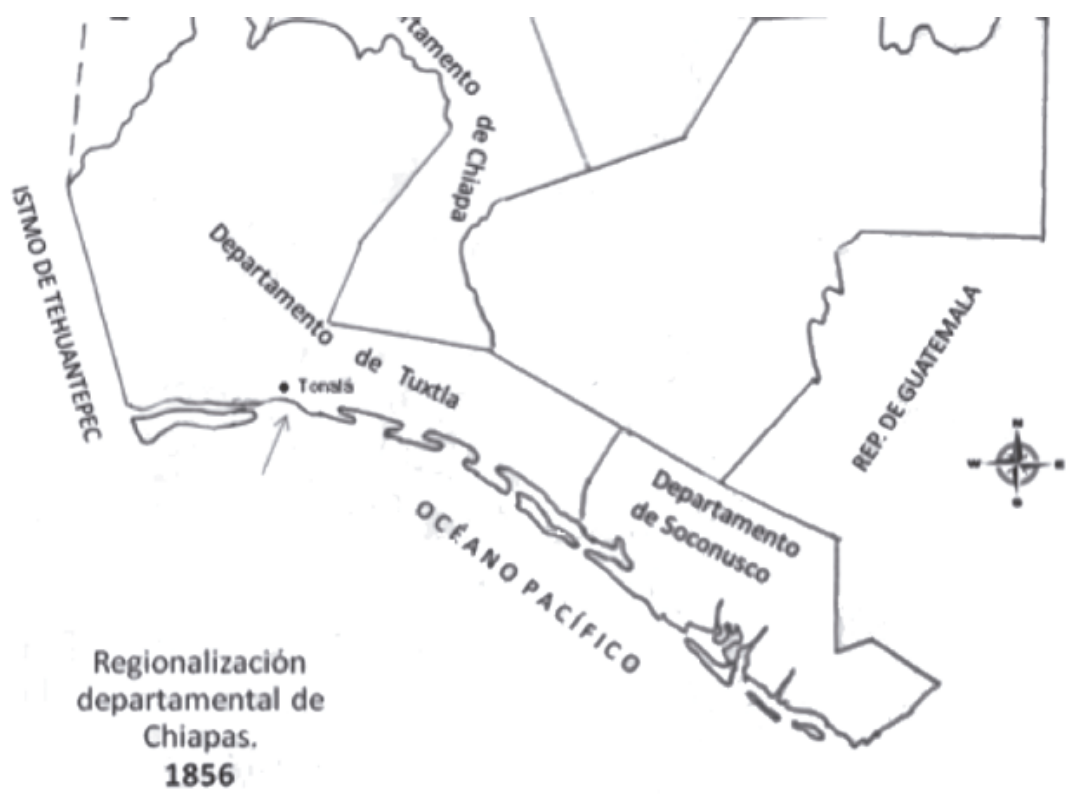

Fuente: elaboración propia con base en la Carta Geográfica de Chiapas (1856), Archivo Histórico de Chiapas.

1 En 1983, el Comité de Planeación para el Desarrollo del Estado (COPLADE) del Gobierno del Estado de Chiapas, regionalizó la entidad en nueve zonas económicas, estableciendo esta denominación.

2 Durante la época colonial, como resultado de las misiones de los franciscanos, el nombre oficial del pueblo era San Francisco de Asís, pero la gente lo conocía como «San Francisco Tonalá». 
A pesar de la distancia, la región tuvo un impulso mercantil debido al decreto del 24 de abril de 1861, del presidente Benito Juárez, que ordenaba habilitar el puerto de Tonalá, conocido como "La Puerta», para el comercio de altura y cabotaje.

De entrada, el puerto fue un atracadero a mar abierto durante casi 30 años; así, recibía a los buques que recorrían el Pacífico desde los Estados Unidos hasta Sudamérica; y en febrero de 1890 se construyó un muelle de 12 metros de profundidad que facilitó el transporte y desembarque de productos y personas, además de una aduana marítima para el registro de los barcos y las mercancías. La actividad en La Puerta fue muy rentable al iniciar el siglo XX; los números de captación de impuestos por concepto de importaciones y exportaciones reflejan intensa actividad económica.

El 6 de diciembre de 1871 surgió una nueva demarcación (figura 2), cuando José Pantaleón Domínguez, entonces gobernador de Chiapas, asignó la cabecera y el nombre de jefatura política departamental al pueblo de Tonalá. Sus linderos iban de la zona limítrofe con Tehuantepec, terrenos conocidos como La Raya (hoy Arriaga), y hacia el sur hasta el pueblo de Mapastepec (hoy municipio), totalizando una superficie de $5738 \mathrm{~km}^{2}$. Esta nueva configuración fue benéfica porque separó a Tonalá del departamento de Tuxtla (cuya cabecera estaba muy alejada), y reafirmó su independencia territorial respecto del Soconusco, departamento vecino cuyos linderos estaban establecidos desde la época prehispánica.

Con esta administración departamental en las tres últimas décadas del siglo XIX la región tuvo actividad continua por vía marítima. Buques nacionales y extranjeros facilitaron el intercambio de productos y el tránsito de personas.

Para 1900, el Departamento de Tonalá tenía diversos asentamientos en su demarcación. Eran los tiempos del presidente Porfirio Díaz con su política basada en el orden y el progreso, que procuraba la introducción de líneas férreas y la promoción de inmigrantes. ${ }^{3} \mathrm{Al}$ departamento de Tonalá llegaron muchos extranjeros en viajes de exploración, como Franklin Everett y Alfred B. Lyon, originarios de Nebraska, Estados Unidos, quienes en 1900 recorrieron la región para una posible inversión ferroviaria, cristalizada en 1902 con la concesión obtenida para construir el Ferrocarril Panamericano4 (Everett 1916).

3 Desde el siglo XIX se manifestó el interés por abrir un canal interoceánico en el istmo de Tehuantepec y explotar las riquezas naturales. Por tanto se promovió a Chiapas ampliamente; para ello se publicaron informes y folletos sobre las condiciones que guardaba el estado.

${ }^{4}$ El periódico The Mexican Herald revelaría años más tarde que la decisión de otorgar a la compañía el nombre de Pan-American Railway correspondió a su condición de último enlace en México 
Figura 2. Regionalización departamental, 1871

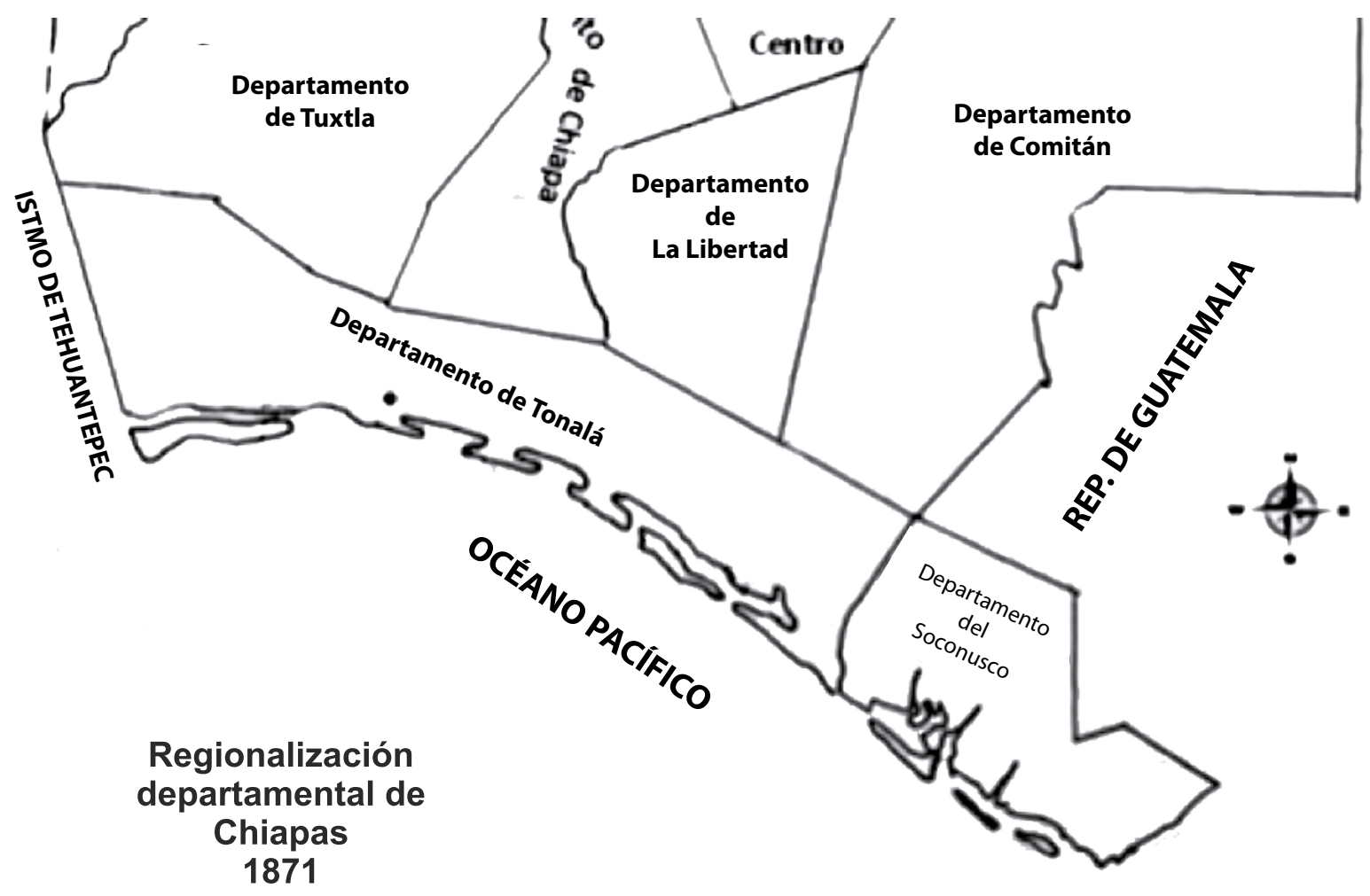

Fuente: elaboración propia con base en la Carta Geográfica de Chiapas (1871), Archivo Histórico de Chiapas.

Entonces inició una abrupta activación en la zona digna de analizarse. El proyecto ferroviario fue, como apunta Mendoza y Díaz (2006), un elemento endógeno que concentró capital humano, elevó el ingreso, generó mano de obra y gran cantidad de actividades laborales.

Efectivamente, hubo mayor rentabilidad de capital, pero fundamentalmente el ferrocarril fue un elemento de cohesión social, que favoreció las relaciones con los demás pueblos de corredor costero, y de enlace con el istmo de Tehuantepec. La vida de muchas familias se circunscribió al tren; se crearon redes laborales, de comercio, de solidaridad y de amistad. De tal forma que se puede hablar de una «región ferroviaria», construida por los mismos actores sociales.

En este entramado social, los acontecimientos fueron muy importantes, como dice Pomian (1998:196), porque tras ellos hubo «una realidad que pervive silen-

del proyecto ferroviario de la primera y segunda Conferencia Internacional Panamericana. Véase The Mexican Herald, marzo 13, 1904 , «The Pan-American Railroad», HMN/FR. 
ciosamente por años y siglos sin que se constate cómo influye en el movimiento de los acontecimientos», siendo a veces, «una especie de cárcel que ata las vivencias de los individuos».

\section{INTENTOS POR INTRODUCIR EL FERROCARRIL}

Durante su segundo periodo presidencial, hacia 1884, Porfirio Díaz impulsaba las inversiones y una de las primeras acciones de su Ministerio de Fomento fue expedir convocatorias para construir ferrocarriles con inversión nacional o extranjera. También en 1884 el gobernador de Chiapas, José María Ramírez, se inclinaba por abrir vías hacia el departamento de Tonalá. Pronto otorgó una concesión para un ferrocarril costero, proyecto no iniciado por su salida de la gubernatura.

Su sucesor, Manuel Carrascosa (correligionario de Porfirio Díaz), continuó con el proyecto del ferrocarril y firmó convenio con la compañía The Mexican Pacific Railroad Limited, formada con capitales de Londres, Nueva York, y Alemania, que construiría una línea de vía ancha con un trayecto «entre el puerto de Tonalá en el Océano Pacífico y un punto conveniente [...] frente al puerto de Frontera [...] ligando a San Cristóbal por la línea principal o por una ramal». ${ }^{5}$

El Congreso aprobó el contrato el 6 de noviembre de 1889 y al siguiente mes iniciaron los trabajos financiados desde Inglaterra por The Baring Brothers, la institución bancaria más exitosa y consolidada de Europa en ese momento.

El 31 de diciembre arribó al puerto de Tonalá el primer vapor con 2000 toneladas de rieles. Para el 13 de febrero de 1890 el muelle de 12 metros de profundidad estaba terminado y en breve arribaron los buques Lonsdak, Moragshire, Balchutha y Havasdale, trayendo 11700 toneladas de rieles, para terminar la obra, y una locomotora. Infortunadamente, en diciembre de 1891 se canceló la construcción porque el banco The Baring Brothers sufrió un fuerte déficit presupuestal.

\footnotetext{
5 Decreto de septiembre 7 de 1889, que aprueba las reformas hechas al contrato de concesión de un ferrocarril de Tonalá a Tuxtla Gutiérrez, celebrado entre el C. general Carlos Pacheco, secretario de Estado y del Despacho de Fomento, el representación del Ejecutivo de la Unión y el Sr. Guillermo Pritchard, en representación de la Compañía Limitada del Ferrocarril Mexicano del Pacífico (The Mexican Pacific Railway Limited) reformando y adicionando los contratos aprobados por decretos en diciembre de 1886 y 28 de mayo de 1888 para la construcción de una línea de ferrocarril del puerto de Tonalá a Tuxtla Gutiérrez, Chiapa y San Cristóbal. Véase <http://cdigital.dgb. uanl.mx/la/1080042593_C/1080043033_T19/1080043033_109.pdf>.
} 
Coyunturalmente, el nuevo gobernador, Emilio Rabasa Estebanell, revisó de entrada las finanzas, encontró irregularidades en los bonos de subsidio y canceló los pagos. La maquinaria y el material rodante que quedó a la intemperie en Tonalá fue resguardado por la Aduana Marítima.

\section{LA ECONOMÍA DEL TREN}

En 1902 resurge la oportunidad de construir el anhelado ferrocarril en Chiapas. La compañía Panamerican Railroad de capital estadounidense obtuvo una concesión de la Secretaría de Comunicaciones para construir la vía, partiendo de San Jerónimo (hoy Ixtepec) Oaxaca, hasta la frontera con Guatemala.

La compañía usó el material rodante que perteneció a The Mexican Pacific Railway Limited ${ }^{6}$ y de entrada construyó el primer tramo de 50 kilómetros entre Puerto Arista y Aurora, ${ }^{7}$ en el Departamento de Tonalá.

La compañía pagaba a cincuenta centavos el jornal diario y contrató a 150 peones, en su mayoría campesinos y vaqueros de ranchos de la región. Con este primer tramo, inaugurado en septiembre de 1902, se envían con más rapidez y capacidad de carga las mercancías a Tehuantepec y Soconusco. Empieza la transportación masiva de caña, ganado, azúcar, carbón, madera y pescado de los ranchos cercanos a Tonalá y la demarcación conocida como el valle de Jalisco (hoy Arriaga).

Los ganaderos empezaron a vender sus semovientes en poblados más alejados y a mejor precio, aprovechando la conexión con las rutas ferroviarias istmeñas. Esto generó que los ranchos y haciendas alejados abrieran nuevos caminos vecinales hacia las paradas.

A partir de la puesta en operaciones del Ferrocarril Panamericano, en 1902, se establecieron tarifas (cuadro 1) de acuerdo con lo estipulado en el convenio original.

\footnotetext{
6 Seis plataformas, seis armones, dos martinetes, una grúa rodante, una sierra movida por vapor, herramientas y dos locomotoras inglesas, una de 20 toneladas para arrastre liviano y otra con peso rodante de 60 toneladas en muy buenas condiciones, con longitud de quince metros, capacidad de leña de siete toneladas y almacenamiento de agua de 3750 galones (Molina 2006).

7 Ranchería ubicada en la zona limítrofe entre Chiapas y Oaxaca, hoy es parte del municipio de Arriaga.
} 
Cuadro 1. Tarifas de carga por kilómetro/tonelada

\begin{tabular}{|c|c|}
\hline Clase & Costo \\
\hline Primera clase & Ocho centavos \\
\hline Segunda clase & Siete centavos \\
\hline Tercera clase & Seis centavos \\
\hline Cuarta clase & Cinco centavos \\
\hline Quinta clase & Cuatro centavos \\
\hline Sexta clase & Tres centavos \\
\hline
\end{tabular}

Fuente: Contrato para la construcción de un ferrocarril que ligue al Ferrocarril Nacional de Tehuantepec con la frontera a Guatemala (artículo 9, tarifa C), agosto 28, 1901, vol. 116/4-1, fs. 1-4, AGN/FSCOP.

Este servicio tenía como topes mínimos una tonelada de volumen y quince kilómetros de recorrido, evidentemente fue proyectado considerando los grandes volúmenes que se transportarían. Las cifras de los primeros tres años de vida del tren reflejan el crecimiento de la actividad económica (cuadro 2).

Cuadro 2. Incremento del tonelaje en el primer año de actividades

\begin{tabular}{|r|r|}
\hline Año & Tonelaje \\
\hline 1904 & 934650 \\
\hline 1905 & 8215265 \\
\hline
\end{tabular}

Fuente: Informes anuales, AGN/FSCOP, en Ortiz (1996:48)

Afirmaba el gobernador Rafael Pimentel en su informe de septiembre (1902:9) que la vía herrada «protegía los intereses comerciales y agrícolas del Estado», y 
el periódico Mexican Herald (editado en la Ciudad de México), afirmaba en 1904 que la vía demostraba ser «exitosa, tanto la carga como el pasaje, que sobrepasa las expectativas de los administradores».

Para 1908, cuando se terminó la construcción del ferrocarril, existía en la región de Tonalá un flujo comercial que generaba ingresos atractivos para la empresa ferroviaria. Por ejemplo, de enero a marzo de 1909 las percepciones netas fueron de 80469 pesos, cifra que se redujo a 49807 netos por los impuestos, contribuciones al gobierno y sueldos a directivos y operarios (Informe de ingresos 19091910, De Wise a Thompsom 1910).

El repunte de la transportación del café fue alto, para marzo de 1910 se habían movido 4067 toneladas a Salina Cruz, desde donde se enviaba a 13 destinos internacionales y cuatro nacionales; se registraron 62466 pasajeros.

Aun con este panorama, el 1 de marzo de 1914 la administración estadounidense traspasa el total de sus acciones al gobierno mexicano, depositados en la empresa Ferrocarriles Nacionales de México (Oficio de traspaso, Secretaría de Comunicaciones y Obras Públicas 1914). En 1915, al irrumpir en Chiapas la acción revolucionaria, disminuyó la dinámica del ferrocarril. Solo la producción de café, maíz y madera salía, resguardada por soldados (Chiapas Nuevo 1917).

A causa del mismo movimiento armado, la vía quedó en malas condiciones, se descuidó la atención en rutas e itinerarios, así como el mantenimiento de rieles y locomotoras, y llegó a ser imposible arreglar múltiples desperfectos del material rodante por el acoso de los asaltantes. En julio de 1917, la Gerencia de Ferrocarril Nacional de Tehuantepec se hizo cargo de la administración del ferrocarril de Chiapas. Al finalizar este año la cosecha anual de café enviada a los puertos antes mencionados fue de 400000 sacos.

\section{NUEVAS DEMARCACIONES}

La región de Tonalá tuvo divisiones territoriales internas producto de los intereses económicos y políticos de sus asentamientos. En 1909 una comisión de vecinos de un grupo de rancherías llamado Jalisco (ubicado en la zona limítrofe con Oaxaca), solicitó al gobernador Ramón Rabasa erigirse en municipio independiente. El 28 de mayo de 1910 el Congreso del Estado aprueba la petición (figura 
3) Obtiene autonomía bajo el nombre de Arriaga, pero supeditado a la Jefatura Política de Tonalá (Periódico Oficial del Estado, Gobierno del Estado 1910b). ${ }^{8}$

Figura 3. Arriaga. Municipio surgido en 1910.

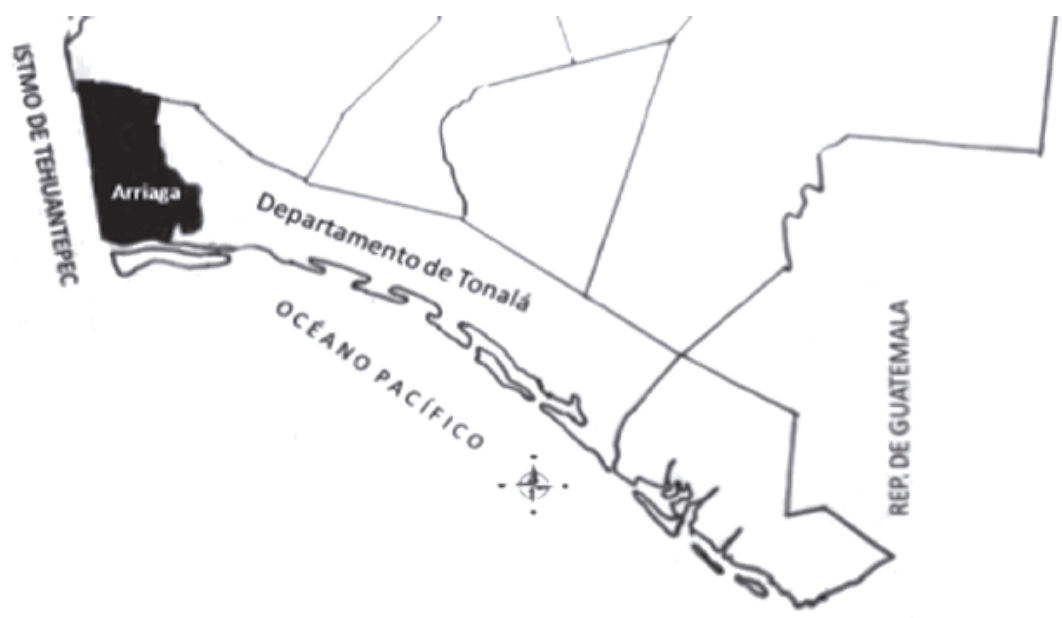

Fuente: elaboración del autor con base en la Carta Geográfica de Chiapas 1856.

Esta separación administrativa respondía a la necesidad de los vecinos del nuevo pueblo de Arriaga de tener sus propias autoridades y consolidar mejoras urbanas y cambios en su territorialidad, pero mantuvieron estrecha proximidad física y enorme convergencia espaciotemporal con sus vecinos de Tonalá.

Otros cambios territoriales y administrativos surgen en 1915 cuando, por decreto gubernamental, desaparecen las jefaturas políticas y se crean 59 municipios libres, entre ellos Pijijiapan y Mapastepec, que al separarse del Departamento de Tonalá, desfragmentaron la vieja territorialidad (figura 4).

8 El 28 de mayo de 1910 el gobernador interino, José Inés Cano (suplía a Ramón Rabasa), aprobó el decreto núm. 12 por el cual «se erige en pueblo que llevará el nombre de Arriaga, la congregación de familias establecidas en el Valle de Jalisco, perteneciente al Departamento de Tonalá». El error de redacción en el decreto al llamarlo «pueblo» en vez de «municipio» no se arregló hasta 1918. El nuevo pueblo de Arriaga se conformó por las haciendas: Jalisco, La Punta, la Calera, Buenos Aires, la Pampa, El Rosario, Santa María, Mal Paso, San Ramón, San Pablo y Aurora. También se incorporaron los ranchos: Las Mercedes, Capulín, Las Gallinas, Cerro Colorado, Río Grande, San Gregorio, Tabasco, Paso Limón, San Antonio, Arroyo del Tigre, Monte Bonito, San Isidro, El Coyol, El Meroche, La Esperanza, Hamburgo, La Libertad, Las Maravillas, Sin Pensar, La Historia, Bola de Oro, La Tapazón, El Desierto, Las Lomas, El Nilo, Las Crucecitas, El Grijalva, Milán, Santo Domingo, Santa Rita, La Gloria, Bella Vista, La Victoria, Punta Flor, La Florida, San Bartolo, Tabasquito, Morelia, El Alba, Villa Mil , San Antonio, El Sosiego, San Felipe, La libertad, Las Marías, Dolores, Rancho Bonito, Solo Dios, El Bosque, Piedra de Cal, La Concepción Carrizal y San Rafael. 
Figura 4. Pijijiapan y Mapastepec.

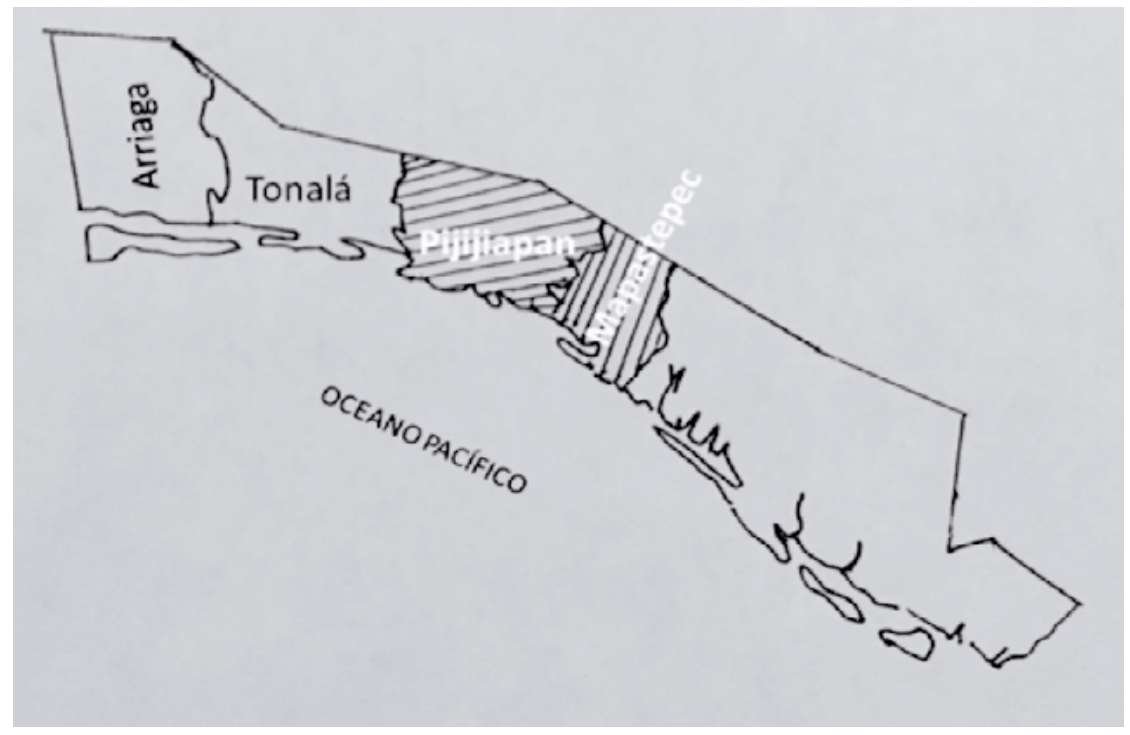

Fuente: Gobierno del estado (1915)

Este hecho político-territorial generó reordenamiento poblacional; los servicios y obras de infraestructura se articularon a los nuevos centros de población, dependientes ahora de las cabeceras municipales en donde se generó más concentración social.

La región de Tonalá fue, a partir de 1915, más identificada con cuatro municipios: Arriaga, Tonalá, Pijijiapan y Mapastepec.

\section{CRECIMIENTO SOCIAL}

La primera década del siglo XX tiene una lectura importante para explicar el crecimiento de la población de inmigrantes en Chiapas. En 1900 se registran corrientes migratorias en la región de Tonalá, como la de 800 chinos para faenas del campo documentada por Kuan (1950); la de estadounidenses ${ }^{9}$ vía marítima, en 1904, que coincidió con un grupo de oaxaqueños. 
Cuadro 3. Número de habitantes por municipalidad. Comparativo censos 1900/1910.

\begin{tabular}{|l|l|c|c|}
\hline \multirow{2}{*}{ Municipalidad } & Categoría & \multicolumn{2}{|c|}{ Totales habitantes } \\
\cline { 3 - 4 } & Ciudad & $\mathbf{1 9 0 0}$ & $\mathbf{1 9 1 0}$ \\
\hline Tonalá & Pueblo & 8934 & 10274 \\
\hline Pijijiapan & Pueblo & 1128 & 3289 \\
\hline Mapastepec & Pueblo & s/d & 2539 \\
\hline Arriaga* & & Total $=12258$ & Total $=19145$ \\
\hline
\end{tabular}

*Arriaga no existía en 1900, era una ranchería adscrita a la jefatura política de Tonalá. Fuente: Gobierno del Estado 1910a.

El crecimiento en la primera década de siglo XX refleja una circunstancia respecto de la región de Tonalá como destino para los extranjeros y comerciantes que buscaban tierras fértiles para iniciar negocios.

\section{CRECIMIENTO SOCIAL Y ECONÓMICO POSREVOLUCIONARIOS}

Existe otra etapa de la dinámica económica y social de la región de Tonalá a partir de 1920, cuando finaliza la Revolución en Chiapas. Aunque ya no existía el Departamento de Tonalá, las nuevas municipalidades aún se circunscribían en muchos sentidos al municipio del mismo nombre, que mantenía su dinámica como cabeza de región y actividad ferroviaria.

El territorio de la región de Tonalá se transformó a raíz del reparto agrario iniciado después de la Revolución. La Ley de mayo de 1921 favoreció a quienes tuvieran capital para establecer ranchos de tamaño pequeño y mediano. El programa federal apoyaba a las congregaciones que tuvieran una condición legal-política como ciudad, villa, pueblo, agencia municipal o congregación, para solicitar la restitución de sus tierras enajenadas ilegalmente o concesionadas.

Surgieron pequeños poblados que subsistían en la medida de su proximidad respecto de las vías del tren; se dota de tierras, por ejemplo, al ejido San Pedro de Los Mangos (hoy Tres Picos) y Pueblo Nuevo (hoy Estación San Cayetano) en Tonalá. En Pijijiapan surgen los ejidos El Vergel, Plan de Ayala, San Antonio, 
Miramar, El Rosario, Francisco Villa, Emiliano Zapata y El Palmar. Y en Mapastepec se forman los ejidos Pino Suárez, Narciso Mendoza, Francisco I. Madero, Santa Isabel, El Carmen, Unión Santa Isabel, 10 de abril, Las murallas, Nuevo Guerrero, Emiliano Zapata y Lázaro Cárdenas.

A partir de 1920 se registra mayor actividad ferroviaria gracias a la reparación de tramos dañados y la sustitución de durmientes y terraplenes. Se instalaron patios y desviaciones para el empalme de locomotoras y se incrementaron los vagones-jaulas de nueve metros que tenían gran almacenamiento y capacidad de arrastre, principalmente para la ganadería.

Al llegar los años treinta las cruzas bovinas hechas por los ganaderos de la región de Tonalá tenían renombre. La administración gubernamental de Francisco J. Grajales (1932-36) favoreció indirectamente al sector pecuario con el reparto agrario, porque generó el crecimiento de los terrenos para pastoreo. También surgieron en este periodo las cooperativas ganaderas en Tonalá, en 1935, con criadores que vivían el furor de la comercialización de razas nuevas.

A partir de 1936, con el gobernador Efraín Gutiérrez, fue más decidido el reparto de tierras, predios que fueron muy poco usados para la agricultura por la humedad de la franja costera y se convirtieron en terrenos para la ganadería extensiva, que basó su éxito en los pastos naturales. Los productores se organizaron en rudimentarias cooperativas en los cuatro municipios de la Costa, adheridas a la Asociación Ganadera Local con sede en Tonalá, que empezó a funcionar en noviembre de 1938.

La década de los cincuenta fue muy próspera. Desde 1948, en Mapastepec se producía cebú puro con la cruzas de ejemplares que trajeron de Texas, y se vendían en 2000 pesos los becerros de seis meses. Arriaga, Tonalá y Pijijiapan fueron en esa década los municipios que más engordas hacían de los novillos flacos de repasto de la zona del Grijalva. Generalmente entre julio y diciembre de cada año se compraban a 190 y 220 pesos por cabeza. En seis meses los hacían pesar entre 350 y 400 kilos, y los vendían generalmente entre enero y junio para el mercado regional o nacional. Sin embargo, los municipios que sacaban ganado gordo todo el año eran Pijijiapan, Mapastepec y Tonalá, gracias a los extensos potreros para criadero y engorda en las praderas de la franja costera.

En 1950 el ferrocarril transportaba hacia otros estados 35000 reses anuales. Carlos Aceituno (Entrevista, 2015), extrabajador de los corrales de salida en Tonalá, afirma que en 1960 se embarcaban diariamente cinco jaulas de reses de 400 kilos. En cada una iban cerca de 30 animales, es decir, se enviaban 150 ca- 
bezas al día. El ganado era enviado a la Ciudad de México; entre 1948 y 1951 la mayor parte se destinada a la Comisión Proveedora de Ganado del Distrito Federal, que actuaba como introductor y rastro, además de administrar y otorgar el subsidio del gobierno federal a los vendedores, a quienes otorgaban preferencia en los vagones-jaulas del ferrocarril para trasladar sus animales desde su lugar de origen. En 1952 esta Comisión se transforma en Administradora de Carnes S. A., y en 1955 se crea la Industrial de Abastos S. A., que manejaba el Rastro de Ferrería, considerado el más grande del país.

El ganadero Alfredo d'Argence, quien inició actividades en 1961 en el rancho Perseverancia, de Tonalá, comentó que ellos embarcaban en Tres Picos (Tonalá) o en Los Patos (Pijijiapan), porque ambas estaciones brindaban seguridad. No existía un seguro por daños o por extravío del ganado que se enviaba al rastro de Ferrería de la Ciudad de México, y por ello él prefería vender al frigorífico que existió en Arriaga (Entrevista, Alfredo d’Argence 2016).

Entre 1950 y 1980 la ganadería registró un crecimiento inusitado, por la ampliación de la superficie ocupada tanto como por el número de cabezas. Tan solo de 1960 a 1970 Chiapas tuvo un crecimiento medio anual de $9.8 \%$ y de $6.4 \%$ entre 1970 y 1976 . Desde luego que este crecimiento no fue igual en todas las regiones. Manuel Velasco Suarez (1970-1976) reconocía en uno de sus informes como gobernador de Chiapas que «las zonas ganaderas más prosperas de la entidad se localizan en la Costa con 700000 hectáreas aproximadamente» (Villafuerte et al. 1997:87-88) y fue el municipio de Mapastepec el que tuvo un acelerado crecimiento con una tasa anual de 10.35 por ciento.

Este segundo momento histórico significó para la región Costa su consolidación como región económica. En los cuatro municipios proliferaron actividades como la «bayunca», consistente en el comercio dentro de los trenes y desempeñado por mujeres; también aparecen oficios como: canasteros, cargadores y carreteros, fabricantes de jabón, los que trabajaban la cera para velas; hojalateros que con lámina hacían quinqués, embudos, anafres; y los herreros que hacían todo tipo de trabajos de metal como rejas, muebles, herramientas, herraduras, etcétera.

Pero la crónica de Esquinca (2010:3) recrea con color esta ambiente:

[...] las corridas del tren eran diarias y la mercancía llegaba en gran variedad: telas de seda, casimir, lino, satín, algodón y cuero del diablo. Jalisco cobró fama por su comercio tan variado, lo mismo habían bodegas que copiaban toda la materia prima, que 
billares, cantinas, tiendas de ropa, tlapalerías. Al comprar en el mercado se escuchaba hablar en dialecto tanto a los chamulas como a las personas del istmo, en las tiendas se hablaba mandarín, en las peluquerías zapoteco y los habitantes en su mayoría español, por lo que llegar a Arriaga era como llegar a otro mundo

La falta de carreteras estatales o federales generó un fenómeno de dependencia económica total del ferrocarril. Surgieron otros medios de transporte que de la capital del estado, Tuxtla Gutiérrez, llegaban a la región de Tonalá, como la línea de pasajes de Juan Campusano, inaugurada en 1925, con carros modestos, y otra de Rogelio Anza, abierta en 1928.

Sin embargo, en la franja costera no había otra opción que el tren, que sobrepasó sus límites de trabajo y realizaba recorridos con el doble de peso permitido, a causa de la gran cantidad de productos que se comercializaban. El Censo Estatal (Gobierno del Estado de Chiapas 1930:10) reconocía que este medio «era insuficiente para aprovechar las grandes posibilidades económicas que el territorio chiapaneco encierra». Era un fenómeno de alta demanda de transporte pero poca capacidad de respuesta de la línea. Las cifras comparativas de cinco años de la década de los cuarenta (cuadro 4) reflejan el acelerado ritmo de crecimiento de la producción.

Cuadro 4. Volumen de salidas de mercancías (en toneladas).

\begin{tabular}{|l|r|r|}
\multirow{2}{*}{ Mercancía } & \multicolumn{2}{|c|}{ A ñ o s } \\
\hline Café & $\mathbf{1 9 4 4}$ & $\mathbf{1 9 4 7}$ \\
\hline Maíz & 25443 & 25527 \\
\hline Ganado & 10046 & 17556 \\
\hline Maderas & 3725 & 4348 \\
\hline
\end{tabular}

Fuente: De la Peña 1951:428-429.

El único alivio a la necesidad de mayor transporte para las mercancías surgió en 1950, cuando entra en funciones la carretera Rancho Bonito-Villafores, que permitía un traslado más ágil hacia Tonalá. En 1953 se inaugura la carretera Arriaga-Tonalá-Puerto Arista, que beneficia el comercio entre estos dos municipios y las comunidades aledañas. Esta línea permitió enlazar con la terracería hacia Tapanatepec y desahogar las operaciones económicas. 
A partir de 1920, una nueva corriente de migrantes extranjeros y de otros estados del país proliferó y aumentó la tasa de natalidad de este sector. Varios chinos avanzaron territorialmente desde Tapachula y Acacoyagua hacia Tonalá y Arriaga, en su mayoría abrieron comercios, dada su tendencia al trabajo organizado. Para 1922 había abarrotes, ferreterías, telas y tlapalería liderados por Enrique Chang, José Long, Manuel Lang y José Tang. En 1929 muchos de ellos militaban en el Partido Nacionalista Chino "Kuo Mi Tango», con sede en Tapachula. Esa organización, más que tener una función política, fue el medio para vincularse con la sociedad. Otros de origen extranjero, como Ángel Dubond, incursionaron en la industria de la transformación; él inició comprando pieles e instaló una tenería.

La colonización y la construcción del ferrocarril propiciaron la presencia constante de grupos de extranjeros. La huella genética de estadounidenses, chinos y negros que pasaron por esta región o que radicaron en ella es evidente en el fenotipo actual de un sector de la población. El proyecto ferroviario llevó a viajeros, científicos, técnicos, cónsules, agentes viajeros, comerciantes, hoteleros y profesionistas que se asentaron en la región. ${ }^{10}$

De ese modo, la llegada de inmigrantes modificó gradualmente el proceso sociohistórico de identidad local colectiva. Durante mucho tiempo, la forma de definir a los grupos sociales de esta zona estuvo ligada a la idea de la presencia de diferentes nacionalidades.

Gran cantidad de naturales chiapanecos de otras regiones sentaron también su residencia en estas cuatro localidades, en su mayoría refugiados por la pasada guerra, hecho que contribuyó al crecimiento de la población (cuadro 5).

El crecimiento en esta región tonalteca fue considerable en 20 años, en virtud del asentamiento de gente de los valles centrales de Cintalapa, Jiquipilas y la Frailesca; y por el oeste arribaron vecinos de Tapanatepec y Juchitán.

Una nueva corriente migratoria surgió en 1976, a raíz de la guerra civil guatemalteca. Miles de refugiados llegaron a territorio mexicano y se diseminaron por los pueblos del corredor costero (López e Ixtacuy 2015:149). También hay registro de 50000 salvadoreños que entraron en territorio mexicano (Del Cid 1992:37). Muchos de ellos, que se establecieron en la región de Tonalá generando un fenómeno de repoblamiento y asentamientos irregulares, fueron calificados como «refugiados» y al paso del tiempo obtuvieron la nacionalidad mexicana.

10 Hay apellidos extranjeros de fuerte arraigo en la región: Ley, Chang, Yong, Long, Lang, Tang, Lau (China); Gellida, Maciel, Betanzos, Burelo (España); Ingui SanMartino, Piconi (Italia); Michaud, Egremy, Grapain, Nivón, Duvón, Gutú, Ricoy (Francia); Cohen (Israel); Tlaye, Patrinos (Líbano); Iwase (Japón). 
Cuadro 5. Habitantes. Comparativo censos 1930/1950.

\begin{tabular}{|l|l|c|c|}
\hline Municipalidad & Categoría & \multicolumn{2}{|c|}{ Total habitantes en los años } \\
\cline { 2 - 4 } & & $\mathbf{1 9 3 0}$ & $\mathbf{1 9 5 0}$ \\
\hline Tonalá & Ciudad & 12993 & 22230 \\
\hline Pijijiapan & Pueblo & 5806 & 10629 \\
\hline Mapastepec & Pueblo & 3079 & 7259 \\
\hline Arriaga & Pueblo & 7450 & 14619 \\
\hline & & Total $=29325$ & Total $=54737$ \\
\hline
\end{tabular}

Fuente: Gobierno del Estado de Chiapas 1930.

El crecimiento de la población en 30 años fue exponencial (cuadro 6), considerando la dinámica de la tasa de natalidad y la presencia de estos inmigrantes que con el paso del tiempo establecían su residencia en algún ejido de la región Istmo-Costa y por alguna razón eran considerados en los censos.

Cuadro 6. Habitantes. Comparativo censos 1960/1990

\begin{tabular}{|l|l|c|c|}
\hline \multirow{2}{*}{ Municipalidad } & Categoría & \multicolumn{2}{|c|}{ Total habitantes } \\
\cline { 2 - 4 } & Tonalá & $\mathbf{1 9 6 0}$ & $\mathbf{1 9 9 0}$ \\
\hline Pijijiapan & Pueblo & 31962 & 67491 \\
\hline Mapastepec & Pueblo & 15886 & 43248 \\
\hline Arriaga & Pueblo & 11790 & 34882 \\
\hline & & 19408 & 36224 \\
\hline
\end{tabular}

Fuente: INEGI 1960, 1990.

\section{ECONOMÍA Y TERRITORIO. LA PRIVATIZACIÓN FERROVIARIA (1960-2000)}

Para 1960 existía un deteriorado y saturado servicio de ferrocarril. Aunque en 1956 se le había cambiado el nombre a Ferrocarril Centroamericano (conocido socialmente como El Pollero) y se le agregaron más espacios para pasajeros, correos y vagones con servicio de primera y segunda clase, el resultado fue mínimo. 
Ni la nueva estación construida en la cabecera municipal de Tonalá entre los años de 1959 y 1960 fue aliciente para un renacer ferroviario.

El servicio más demandado era el de carga: se transportaba ganado, cemento, costales de maíz, sorgo, frijol, ajonjolí, madera, entre otros productos. Sin embargo, la demora de los carros, los descarrilamientos por el reblandecimiento de los terrenos e incluso los asaltos en varios puntos del recorrido, ocasionaba que varios sectores productivos optaran por un medio de comunicación más eficiente para el traslado de sus productos.

En 1964 se inaugura la tan esperada carretera Arriaga-Tapachula. El impacto de esta línea fue importante en toda la región tonalteca porque dio oportunidad para una comunicación más rápida con el centro del país y que todos los productos agrícolas y ganaderos salieran con prontitud (Pagola 1952). Y aunque ese mismo año la administración del ferrocarril puso en operaciones las máquinas de diesel que, además de ofrecer rapidez, estrenaban el servicio de pasajeros pullman con restaurante, fueron poco usadas y se deterioraron rápidamente.

En los años setenta, el investigador Ángel Bassols Batalla (1971:151), en su extenso y bien documentado trabajo de campo en esta región, observó que la
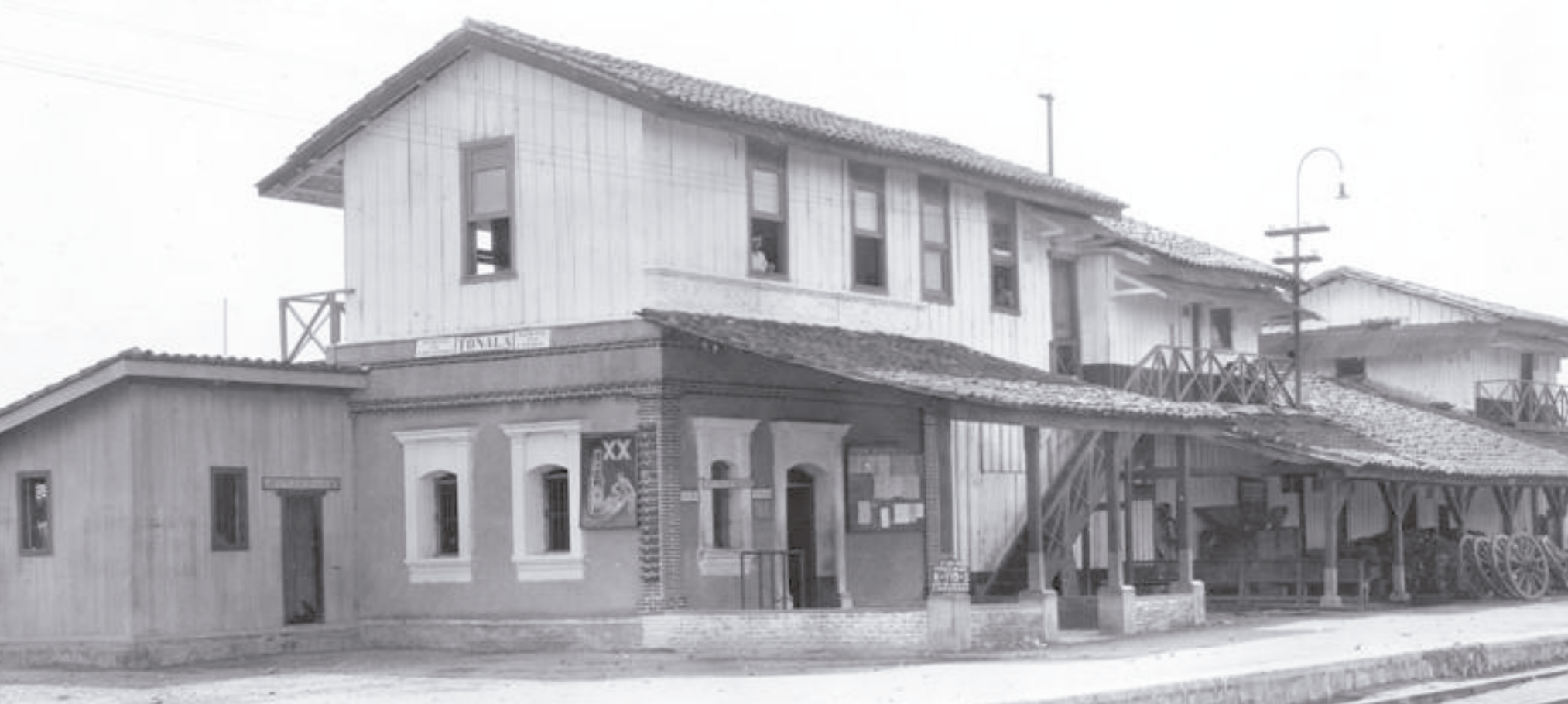

Plaza del pueblo de Tonalá, Chiapas, 1900. Archivo Personal de Sofía Mireles Gavito, cronista de Tonalá. 


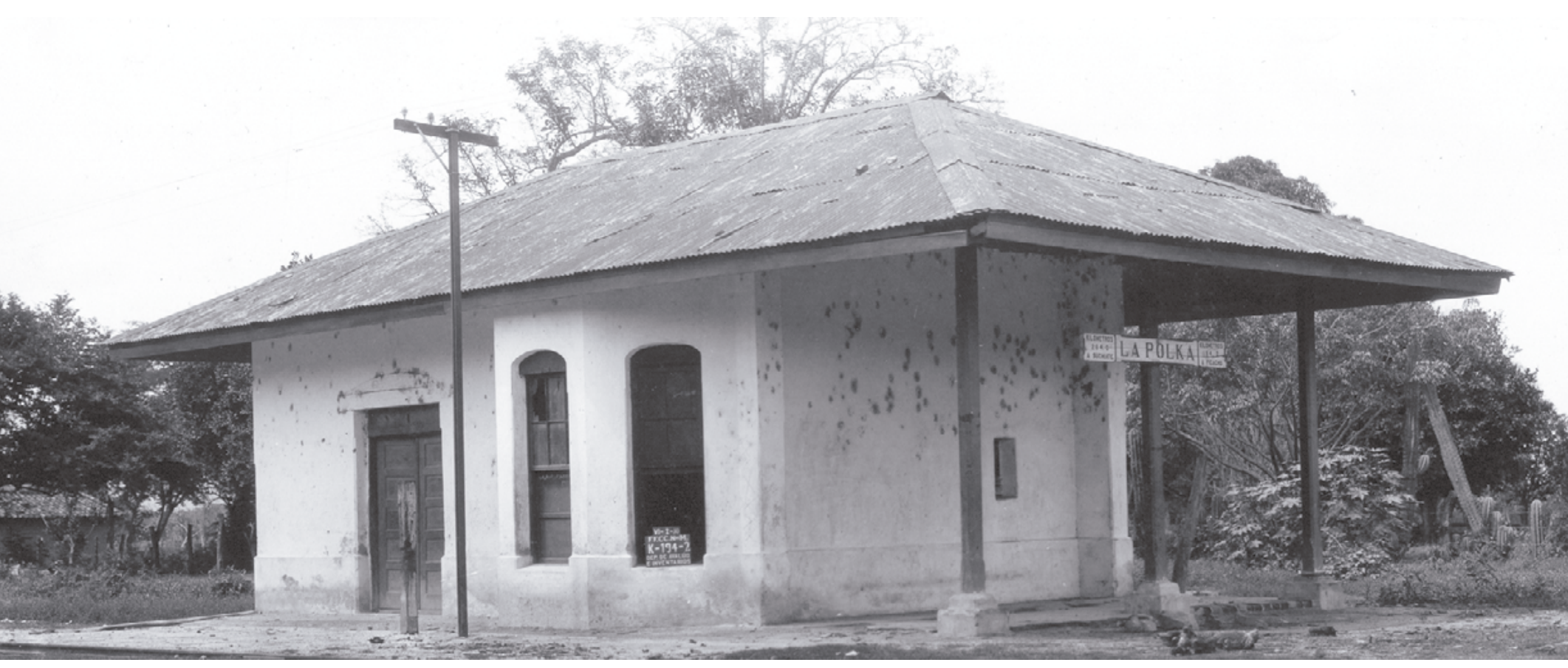

Estación del ferrocarril Panamericano, junio, 1935. Fototeca del Centro de Difusión e Investigación Ferroviaria (CEDIF) del Museo Nacional de los Ferrocarriles, Conaculta.

transportación del ganado y los granos se realizaba cada vez más en camiones y afirma en su análisis después de un año de observación:

[...] el tren es demasiado lento en comparación con la carretera que corre al paralelo; siendo que esta última ha venido a arruinar en gran medida a dicho ferrocarril, mismo que se sabe que resulta anticuado, en su equipo y material rodante. Por esta razón pensamos que la ineficiencia del ferrocarril constituye otra traba más para el desenvolvimiento industrial de la zona, y dentro de cualquier programa de desarrollo industrial, su modernización y reacondicionamiento involucrarían fuertes inversiones adicionales.

La actividad comercial que desde la segunda mitad del siglo XX se mantuvo sólida en la región de Tonalá fue la ganadería extensiva (cuadro 7). Las fincas de ganado vacuno proliferaron. 
Cuadro 7. Distribución del ganado vacuno en Tonalá, 1960

\begin{tabular}{|l|c|}
\hline Territorio por extensión y denominación & Cabezas \\
\hline Total en el municipio & 37148 \\
\hline Ranchos mayores a 5 hectáreas & 29852 \\
\hline Ranchos de 5 hectáreas o menos & 311 \\
\hline Ejidos & 3817 \\
\hline Ganado en poblaciones & 3168 \\
\hline & Total: 74296 \\
\hline
\end{tabular}

Fuente: Gobierno del Estado 1960.

Para 1970 la ganadería ocupaba 68.99 \% de la actividades productivas en la región. Es justamente ese año cuando la empresa Nestlé instala una planta captadora. La economía tonalteca se orienta a nuevas actividades como la industrial, que encuentra en la región mano de obra barata. En Paredón, por ejemplo, se construye una fábrica de vidrio, y en 1973 inicia operaciones el Centro de Acuacultura en Tonalá, dependiente de la Secretaría de Agricultura y Recursos Hidráulicos, cuya actividad favorecía el incremento de captura de productos del mar, ${ }^{11}$ más para consumo estatal (Semarnap 1997).

La deficiencia en la administración y el servicio del ferrocarril era evidente. Inicia entonces el reordenamiento poblacional alejado de las estaciones, nuevos intereses económicos y una dinámica de desarrollo social diferente, enfocada a las carreteras pavimentadas. Este proyecto fue beneficiado por la nueva regionalización impulsada por el Comité de Planeación para el Desarrollo del Estado (COPLADE) en 1983, que dividió al estado en nueve regiones económicas. El Gobierno se basó en la regionalización de finales de siglo XIX para hacer nueve demarcaciones. El territorio que analizamos fue denominado Istmo-Costa (figura 5), desde Arriaga hasta Mapastepec.

11 El volumen de la captura en Chiapas tuvo una tendencia creciente de 1985 a 1991, con una tasa media de crecimiento de $7 \%$ anual. 
Figura 5. Región IX Istmo-Costa.

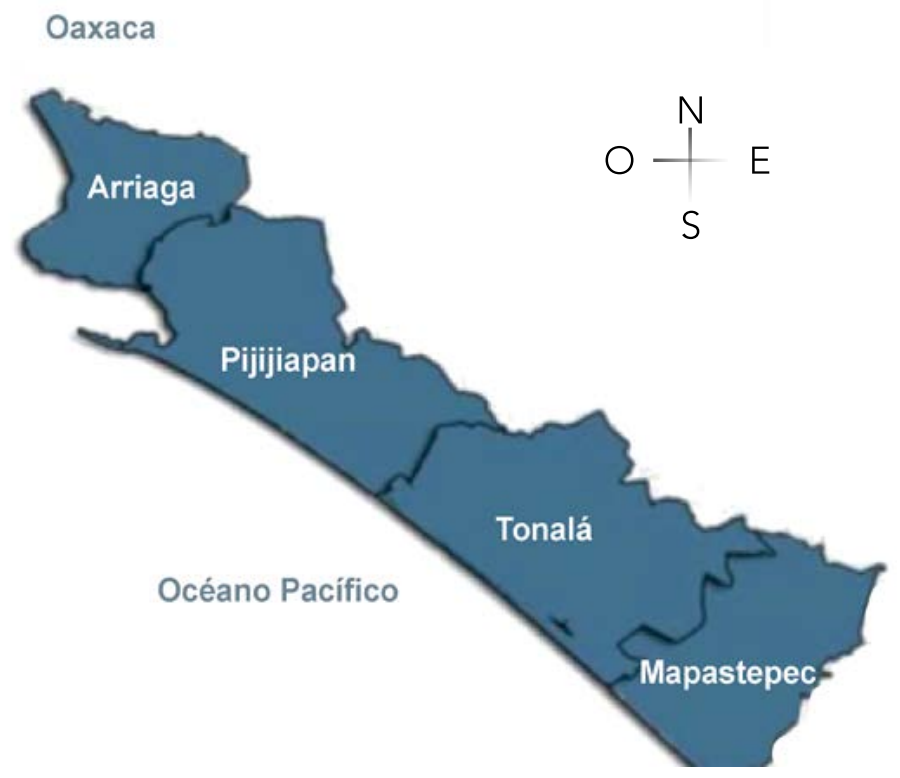

Fuente: Elaboración propia, a partir de datos Inafed (2010).

A partir de esta regionalización se inician otras actividades, como la producción de mango de traspatio en una infinidad de terrenos ejidales. En los años ochenta se sembraron en esta región 5000 hectáreas de mango en un contexto político y económico nacional diferente al que se presentaba con el auge del café o del plátano (Fletes 2013:126-127).

Para estas actividades económicas, el ferrocarril ya no era el medio de transporte idóneo, las carreteras pavimentadas y los vehículos automotores eran contratados para sacar mercancías agrícolas y pecuarias. En 1987 el gobierno mexicano decidió fusionar las líneas férreas de Centro, Sur, Pacífico, Pacífico norte, Sureste y Noreste en una sola entidad, y creó una gerencia para cada una de las regiones en que dividió el sistema de Ferrocarriles Nacionales de México. Y en 1995 se anuncia su privatización.

El ferrocarril de Chiapas fue concesionado el 26 de agosto de 1999 a la empresa estadounidense Chiapas-Mayab S. A. de C. V., que le da un giro a esta vía y la convierte exclusivamente en medio de carga, con precios elevados, y eso genera el cierre de empresas locales que no tenían posibilidades de otro medio de transporte. 


\section{REFLEXIONES FINALES}

No es difícil dilucidar el nuevo orden social y económico generado a la par de la reconfiguración de la región de Tonalá con la presencia del ferrocarril. Este fue el hilo conductor de hechos relacionados con el sistema de vías y el desarrollo económico y social durante el siglo XX en marcadas etapas.

El decaimiento del ferrocarril en los años cincuenta hizo que la región evolucionara hacia otros elementos identitarios sociales, formas de relación de producción y reordenamiento territorial al construirse la nueva carretera costera.

El tren se convirtió entonces en una mera referencia histórica local de desarrollo y se vinculó socialmente como un suceso de identidad colectiva que aludía al origen económico del siglo en la costera, un hecho local incrustado en el ideario y formado como un cinemascope épico y un tanto borroso, pero como la más clara muestra de la reinterpretación de los hechos al paso del tiempo.

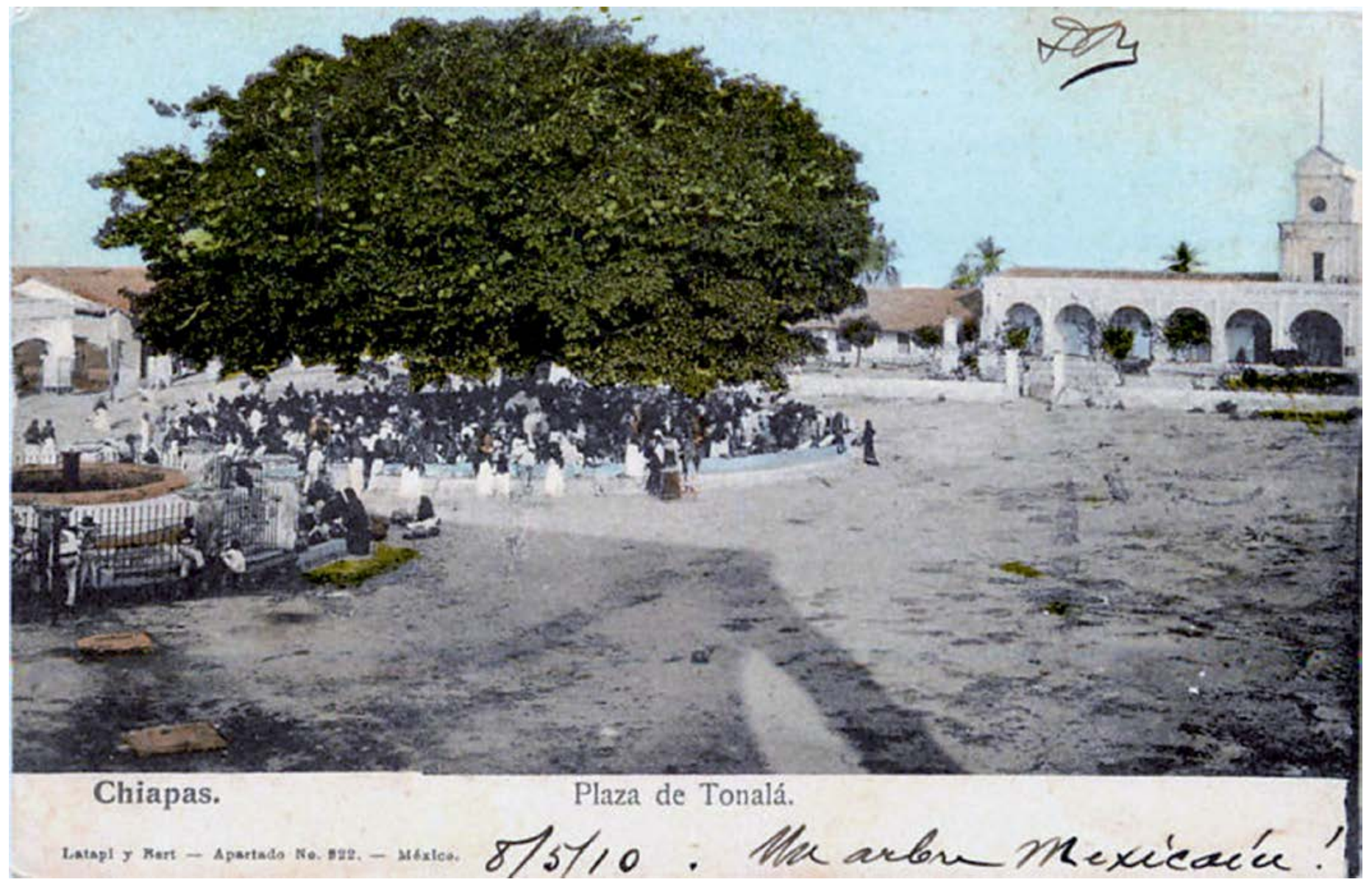

Estación La Polka, junio, 1935. Fototeca del Centro de Difusión e Investigación Ferroviaria (CEDIF) del Museo Nacional de los Ferrocarriles, Conaculta. 
Después de 1950 la presencia del ferrocarril en la región de Tonalá no era de contribución significativa; por lo tanto, la dinámica económica se reorientó a otras maneras de transporte y el aspecto social giró en torno a otras vías de comunicación. Tonalá como cabecera de distrito estuvo entonces más apegada a las respuestas de un desarrollo estadocéntrico que a las bondades de la comunicación ferroviaria.

Es importante conocer los hechos particulares de la región de Tonalá o IstmoCosta, pues son el reflejo de una situación similar vivida en otras zonas de Chiapas. Juan Pedro Viquiera (2008:52) apunta que «Una verdadera historia nacional que busque dar cuenta de la diversidad existente en el territorio mexicano tiene, pues, que construirse a partir de una amplia colección de historias locales o regionales».

La región de Tonalá ha sido un territorio cambiante en las dimensiones económica y social. Por lo tanto, vale la pena explorar el comportamiento de una estructura regional que destaque ciertos hechos en el tiempo y que brinde indicios de la trayectoria que seguirá con los proyectos del presente.

Haciendo una analogía entre los discursos de los siglos XX y XXI, es trascendente ver el interés que existe por parte del Estado sobre la capacidad productiva de la región de Tonalá. Al referirse a la región Istmo-Costa, la asumen como un territorio de potencial para producir mercancías agrícolas y fortalecer la economía estatal.

Los medios de comunicación terrestre siguen siendo muy importantes para consolidar los proyectos de desarrollo y las relaciones comerciales. Y el ferrocarril, con sus altibajos, sigue siendo un medio socorrido para el traslado de mercancías. Pareciera que el tiempo le ha otorgado una posición indisoluble incrustada en la económica y social.

\section{FUENTES DE CONSULTA}

Bassols Batalla, Ángel, 1971, La Costa de Chiapas. (Un estudio económico regional), México, Instituto de Investigaciones Económicas-Universidad Nacional Autónoma de México.

Carta Geográfica de Chiapas, 1856, México, Mapoteca del Archivo Histórico de Chiapas. 1871, México, Mapoteca del Archivo Histórico de Chiapas.

Chiapas Nuevo, 1917, "Información del corresponsal de Tapachula», p. 1. 6 de mayo de 1917, México, Archivo Histórico de Chiapas, Hemeroteca Fernando Castañón Gamboa. 
Cid, J. R. del, 1992, «Migración interna e internacional en Centroamérica», en Rodolfo Casillas R. (comp.), Los procesos migratorios centroamericanos y sus efectos regionales, México, Facultad Latinoamericana de Ciencias Sociales.

Dublá, Manuel y José María Lozano (eds.), Legislación mexicana. Colección completa de las disposiciones legislativas expedidas desde la independencia de la República, t. XIX, México, Imprenta y Litografía de Eduardo Dublán y Comp., 1887, p. 542, disponible en: http://cdigital.dgb.uanl.mx/la/1080042593_C/1080043033_ T19/1080043033_109.pdf

Esquinca Camacho, Eloy, 2010, Recopilación de información sobre la historia de Arriaga, Por amor a nuestra Tierra, México, Respetable Logia Simbólica, "Ángel Albino Corzo \# 7».

Everett, Fremont, 1916, Some of the Everetts, Portland Oregon, Press of Glass \& Prudhomme Co.

Fletes Ocón, Héctor B., 2013, Construyendo la globalización: estado, mercado y actores de las cadenas agroindustriales de mango desde Chiapas, Tuxtla Gutiérrez, Universidad Autónoma de Chiapas.

Gobierno del Estado de Chiapas, 1910a, Censo y División Territorial, Archivo Histórico de Chiapas, Biblioteca Víctor Manuel Castillo, Tuxtla Gutiérrez, Universidad de Ciencias y Artes de Chiapas.

1910b, «Proyecto de Acuerdo», núm. 25, t. XXVII, lib. 35, pp. 283, 284, Periódico Oficial del Estado, Histórico de Chiapas, Tuxtla Gutiérrez, Hemeroteca Fernando Castañón Gamboa.

1915, «Declaración de Municipio Libre», Periódico Oficial del Estado, 8 de enero.

1930, Quinto Censo de Población, Archivo Histórico de Chiapas, publicado el 15 mayo de 1930, vol. II, t. VII, Biblioteca Víctor Manuel Castillo, Tuxtla Gutiérrez, Universidad de Ciencias y Artes de Chiapas.

1960, Censo Agrícola y Ganadero del Estado de Chiapas, Archivo Histórico de Chiapas, Biblioteca Víctor Manuel Castillo, Tuxtla Gutiérrez, Universidad de Ciencias y Artes de Chiapas.

Holscher, Lucian, 1997, "The new annalistic: a sketch of a theory of history», History and theory, 36(3), pp. 317-335.

Kuan, Ming Chen, 1950, Chinos en Latinoamérica, Costa Rica, Flasco (Cuadernos de Ciencias Sociales, 124).

Instituto Nacional para el Federalismo y el Desarrollo Municipal, 2010, Enciclopedia de los Municipios, México, Secretaría de Gobernación, <http://www.inafed.gob.mx/ work/enciclopedia/EMM07chiapas/index.html> [consultado: 15 de mayo de 2015].

Instituto Nacional de Estadística y Geografía, 1960, México, Censos Generales de Población de 1960.

1990, México,Censos Generales de Población de 1990.

López Arévalo, Jorge y Octavio Ixtacuy, 2015, Guatemala-Chiapas: Economía y Frontera, Tuxtla Gutiérrez, Universidad Autónoma de Chiapas.

Mendoza, Jorge Eduardo y Alejandro Díaz Bautista, 2006, «Evolución de le teoría y de la práctica del análisis económico regional», en Economía regional moderna. Teoría y 
práctica México, El Colegio de la Frontera Norte/Universidad de Guadalajara/Plaza y Valdés, pp. 9-38.

Molina Pérez, Valente, 2006, Por los rieles de Chiapas. Construcción del Ferrocarril Panamericano, México, Sistema Chiapaneco de Radio y Televisión/Editorial Edysis.

Ortiz Hernández, María de los Ángeles, 1996, «Propietarios y café en el Soconusco: el Ferrocarril Panamericano», en Siglo XIX, 14, enero-abril.

Pagola Reyes, Felipe, 1952, "Carretera costera Arriaga-Tapachula», Ponencia presentada ante el V Congreso General Extraordinario de la Federación de Trabajadores del Estado de Chiapas, México, CTM.

Peña, Moisés T. de la, 1951, Chiapas Económico, México, Gobierno del Estado de Chiapas.

Pimentel, Rafael, 1902, Informe, septiembre 15, Tuxtla Gutiérrez, Imprenta del Gobierno del Estado de Chiapas.

Pomian, Krzystof, 1988, La historia de las estructuras, en Enciclopedias del Saber Moderno, Bilbao, Diccionario de la Nueva Historia.

Secretaría de Comunicaciones y Obras Públicas, 1914, Oficio de traspaso del PanAmericano al FNM, marzo 7, 1914, volumen 237/2-1, foja. 71, Ciudad de México, Archivo General de la Nación, Fondo de la Secretaría de Comunicaciones y Obras Públicas.

SemarnaP, 1997, Anuario Estadístico de Pesca, México, Dirección de Estadística y Registro Pesqueros.

The Mexican Herald, 1904, "The Railway», México, Fondo Reservado, Hemeroteca Nacional, UNAM, 23 de noviembre.

Villafuerte Solís, Daniel, María del Carmen García y Salvador Meza, 1997, La cuestión ganadera y la deforestación. Viejos y nuevos problemas en el trópico y Chiapas, Tuxtla Gutiérrez, UNICACH-Centro de Estudios Superiores de México y Centroamérica.

Viqueira, Juan Pedro, 2008, «Indios y ladinos, arraigados y migrantes en Chiapas: un esbozo de historia demográfica de larga duración», en Daniel Villafuerte y María del Carmen García (coords.), Migraciones en el sur de México y Centroamérica, México, UNICACH/Miguel Ángel Porrúa Editor, pp. 275-322.

Wise a Thompsom, 1910, «Informe de ingresos 1909-1910», marzo 26, 1910, expediente 7-5159, legajo 2, caja 39, Museo Nacional de los Ferrocarriles, Centro de Investigación Ferroviaria, Fondo de la Junta Directiva, Puebla de los Ángeles, Puebla.

\section{Entrevistas}

Alfredo d'Argence Morell, 15 de enero de 2016, Tuxtla Gutiérrez Carlos Aceituno, 11 de marzo de 2016, Tonalá, Chiapas.

Fecha de recepción: 18 de noviembre de 2015

Fecha de aceptación: 19 de abril de 2016 